\title{
Female Sex Workers and Their Association with Self-Help Groups in Thane, Maharashtra, India: A Comparative Analysis in the Context of HIV Program Outcome
}

\author{
Awdhesh Yadav, Saravanamurthy P. Sakthivel, Shaikh Tayyaba, Uma Shah, Ashok Agarwal \\ Public Health Foundation of India, New Delhi, India \\ Email: awdhesh.stat@gmail.com
}

How to cite this paper: Yadav, A., Sakthivel, S.P., Tayyaba, S., Shah, U. and Agarwal, A. (2016) Female Sex Workers and Their Association with Self-Help Groups in Thane, Maharashtra, India: A Comparative Analysis in the Context of HIV Program Outcome. World Journal of AIDS, 6, 186-196. http://dx.doi.org/10.4236/wja.2016.64021

Received: September 21, 2016 Accepted: December 11, 2016

Published: December 14, 2016

Copyright $\odot 2016$ by authors and Scientific Research Publishing Inc. This work is licensed under the Creative Commons Attribution International License (CC BY 4.0).

http://creativecommons.org/licenses/by/4.0/

\begin{abstract}
Objectives: Understanding the role of Self-Help Group (SHG) in light of the evolving dynamics of sex work needs to be delved into to strategize HIV interventions among FSWs in India. This paper aims to study the HIV program outcome among the FSWs associated with SHGs and FSWs not associated with SHGs in Thane, Maharashtra. Study Design: This cross-sectional study was undertaken from the Behavioral Tracking Survey (BTS) conducted among 503 FSWs in Thane in 2015. Two-stage probability based conventional sampling was done for selection of brothel and bar based FSWs, while Time Location Cluster (TLC) sampling was done for home, lodge and street based sex workers. Methods: Bivariate and multivariate logistic regression were performed to compare and contrast between FSWs associated with SHG and those not associated with SHG with respect to the utilization of HIV related services by them. "Condom use", "consistent condom use", "contact with peer-educators", "counseling sessions" and "HIV testing" were chosen as indicators on HIV service utilization. Results: $8 \%$ (38) of FSWs are registered with SHG; $92 \%$ aged $\geq 25$ years, $47 \%$ illiterate, and $71 \%$ are currently married. The likelihood of utilizing HIV services including, knowledge on HIV/AIDS and its mode of transmission (OR: 5.54; CI: 1.87 - 16.60; $\mathrm{p}<0.05$ ), accessed drop-in Centre (OR: 6.53; CI: 2.15 - 19.88; $\mathrm{p}<0.10$ ), heard about joint health camps (OR: 4.71; CI: $2.12-10.46$ ); $\mathrm{p}<0.05$ ), negotiated or stood up against police/broker/local goonda/clients (OR: 2.26; CI: 1.08 - 4.73; p < 0.05 ), turned away clients when they refused to use condom during sex (OR: 3.76; CI: 1.27 - 11.15; p < 0.05) and heard of ART (OR; 4.55; CI: 2.18 - 9.48; p < 0.01) were higher among FSWs associated with SHG in comparison to FSWs not associated with SHG. Conclusions: Considering the improved HIV program outcomes among
\end{abstract}


FSWs associated with SHG, HIV interventions among FSWs could consider facilitating the formation of SHGs with FSWs as one of the key strategies to empower the community for ensuring better program outcomes.

\section{Keywords}

Female Sex Workers, Self-Help Group, HIV, Thane, Empowerment

\section{Introduction}

Poverty, gender inequalities and social marginalization continue to be a major challenge globally to HIV prevention efforts particularly among key populations. Current literature indicates that economic insecurity of women and their dependence on men increase their vulnerability to HIV by limiting their agency to negotiate the conditions for safer sex [1]. Studies in India show that women either involve in sex work involuntarily, often due to economic reasons [2] or they are forced into sex work [3] [4]. Women who join sex work for economic reasons belong to a particular social, caste and class groups. Studies that have profiled the socio-demographic characteristics of sex workers [3] [5] [6] [7] [8] document that the majority of women in sex work are illiterate, belong to lower castes, are destitute and/or are from poor economic backgrounds. Female sex workers (FSWs) are considered as one of the key populations for HIV transmission due to various occupational hazards such as sex with multiple partners, inconsistent condom use, and higher infection rates [9] [10]. HIV prevalence in India is also estimated to be more than 20 times higher among sex workers as compared to the general population [11] [12] [13]. Further, understanding on HIV/STI risk among FSWs requires focused attention to examine the contextual factors, including but not limited to, individual risk behavior, social and structural factors impede the community to act on their choice. FSWs are not empowered, socio-economically marginalized and are highly vulnerable to HIV [14].

Self-Help Groups (SHGs) in India, is conceived as a strategy to bring together women from socially under privileged section of the society and empower them with information and opportunities for economic securities. SHGs comprise of members who share the same local context, life situation or crisis. Members provide emotional support to one another, learn new ways to cope, discover strategies for improving the well-being of their children, and overall help other members while helping themselves. SHG members who share common shame and stigma can come together, without judging, or to provide an "instant identity" and community [15]; combat together. Through participation, they can enhance their social skills and promote their social rehabilitation [16]. Over a period, this strategy has proved to be successful, and HIV program has leveraged SHG, for reaching out to the women in general population and this has been extended to FSW [17] and People Living with HIV/AIDS (PLHAs) [18] for ensuring favorable HIV program outcomes. 
In developing countries, the studies emphasize the importance of SHGs in empowering FSWs and in reduction the risk \& vulnerability to STI/HIV [19] [20] [21]. The additional benefit is that such group can play an important role in addressing HIV prevention behaviors such as safe sex practices, HIV status disclosure and condom use to decrease the spread of the disease [22]. Literature suggests that developing countries may continue to establish similar kind of groups as one of the structural intervention approaches to combat HIV/AIDS. Literature on the role of SHGs in generating awareness and exposure to HIV/AIDS prevention interventions among FSWs in developing country like India is limited, with focus on community mobilization, social capital and social support [21] [23].

In India, Maharashtra ranks among the top four states with $0.37 \%$ of HIV prevalence among adults aged 15 - 49 years, higher than the national average of $0.26 \%$ [11] and it is 7.4\% among FSWs [24]. Thane district in Maharashtra, has prevalence of HIV (5.2\%) among FSWs and a moderate prevalence (0.50\%) among the general population [25], coupled with high population size of FSWs (15,500), MSM (4827), TG (2020), IDU $(688)$ and Migrants $(935,285)$ due to which, it is the high focus area for HIV program designers. Considering the high HIV burden in Thane district, the HIV/AIDS Partnership: Impact through Prevention, Private Sector and Evidence-based Programming (PIPPSE) Project, supported by United State Agency for International Development (USAID), is working since 2012 for implementing the HIV prevention program under District Network Model (DNM) in the district under the aegis Maharashtra State AIDS Control Society (MSACS) [10].

This paper analyses the role of SHG as a structural intervention strategies in empowering FSWs in addition to improving the key HIV program outcomes, including, but not limited to, awareness, access to HIV/STI testing, treatment services and condom usage.

\section{Methods}

Study Design and Participants: This was a cross-sectional study, drawn from Behavioral Tracking Survey (BTS), conducted in Thane district of Maharashtra, India, during September-October, 2015. Non-Government Organizations (NGOs); working in developmental activities, including health and non-health, predominantly, without making any financial profit have been the forerunners in India, in creating awareness on HIV from the initial stages of this epidemic and gradually implemented HIV prevention activities among HIV associated High Risk Groups (HRGs). Twelve NGOs implementing HIV prevention services to FSWs in Thane, prior to April 2014, were considered for development of sampling frame for the study; and facilitating the recruitment of study population in Thane.

\subsection{Sampling}

The sampling frame (FSW sites) was developed by accessing information on the hotspots (geographical area), where there is significant concentration of HRGs are found 
[26] from the 12 NGOs implementing HIV prevention interventions among FSWs in Thane. A total of 375 active hotspots with 5 or more FSWs as of July 2015 were identified by HIV prevention intervention implementing organizations. The sampling frame was further segregated by typology of FSWs-Brothel, Bar, Home and Street. In order to reach 500 FSWs, it was decided to select 100 Primary Sampling Units (PSUs)/hotspots, and cover 5 FSWs per selected site; 60 conventional clusters and 40 time-location clusters were selected from the PSU using population proportionate to size approach on the number of hotspots. Two-stage probability based conventional and time-location cluster sampling approach were adopted to sample 503 FSWs from brothel, bars, street and home based settings. The sampling procedure is presented in the flowchart (Figure 1) for reference.

\subsection{Variables}

Outcome Variables: Considering the level of exposure to intervention may vary widely in existing literature, self-reported data were collected using a questionnaire on exposure to HIV/AIDS and its mode of transmission, Knowledge on modes of prevention of HIV/AIDS, contacted by outreach worker to provide STI/HIV/AIDS information, received condom from NGO/TI, visited drop-in center, received counselling from a TI on STI, HIV, condom use and safe sex practices, visited NGO clinic/ TI-doctor for routine medical checkup and counselling for STIs, heard any health camp where individual from different typologies or different health provider assemble, received/accessed any services from joint health camp in last 12 months, number of times visited health camp in the last 12 months, has turned away clients when they refused to use condom during sex, negotiated or stood up against police/broker/local goon$\mathrm{da} /$ client and heard of ART.

Covariate Variables: The primary variable of interest was "are you a member of self-help group (No, Yes)", however we also include others variables as the potential

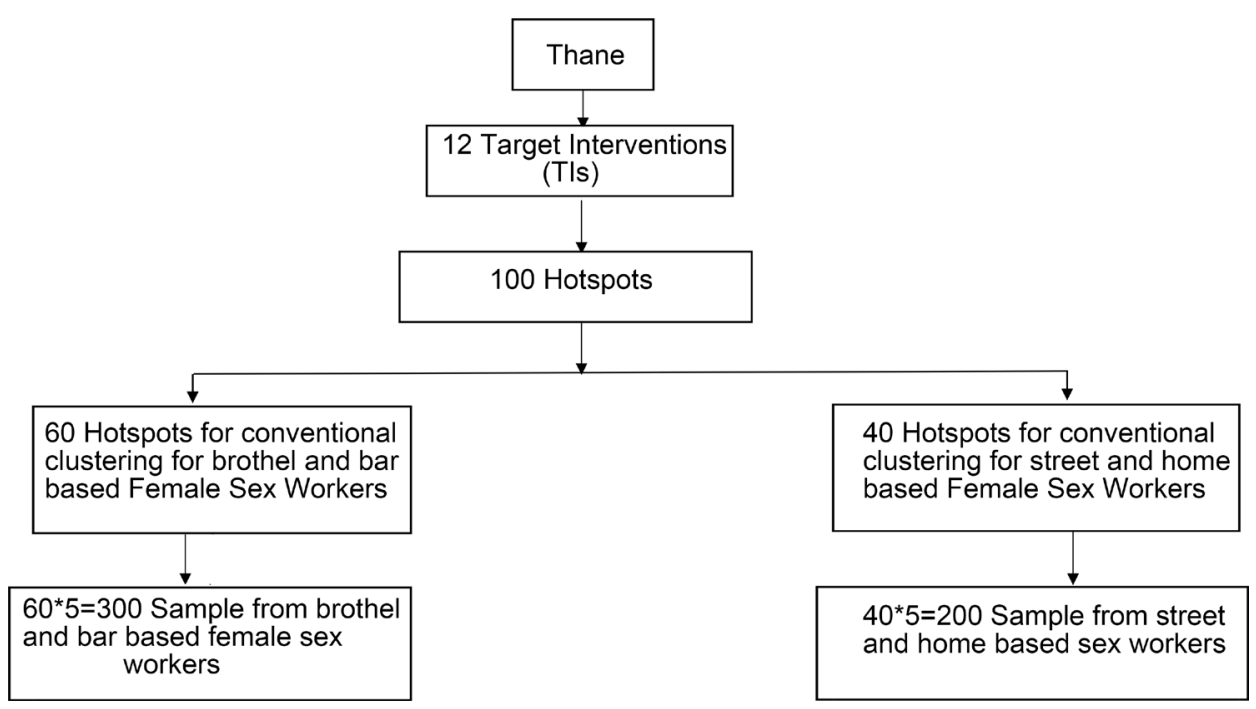

Figure 1. Flow chart on sampling. 
confounders. Like, age ( $<25$ years and $>=25$ years), education (Illiterate, Primary, Secondary and Upper-secondary and more), marital status (Never, Married, currently married and widowed/Divorced/Separated), source of income other than sex (No, Yes), age at first sexual intercourse ( $<20$ years, $>=20$ years), age at first selling sex work $(<20$ years, $>=20$ years), number of occasional clients (clients who came to you only once or a few times more but you do not remember their face or do not know them) in seven days , ever had physical or sexual violence (No, Yes) were considered.

\subsection{Data Analysis}

Data were manually entered in CSPro 6.1 software and were cross-checked for duplication. Descriptive statistics of socio-demographic profile of the study participants were calculated using STATA 13. Bivariate analysis was carried out to understand the proportion of SHG against Non-SHG FSWs by selected background characteristics. Chi squire was used to test the significant difference among SHG and Non-SHG by selected characteristics. In addition to that difference between means was assessed using Wilcoxon Mann-Whitney Test. All test were two sided and a p-value of $<0.05$ was considered statistically significant. Multiple logistic regression was performed to assess the role of SHG on HIV prevention. The significant association between HIV/AIDS related services and SHG was further considered for adjusted multiple logistic regression.

\section{Results}

The mean age of the study participants is 30 ( $\mathrm{SD}=6.0$ ) years, while FSWs associated with SHG was $32(\mathrm{SD}=5.5)$ years significantly $(\mathrm{p}=0.031)$ higher than the mean age of FSWs not associated with SHGs. The participating FSWs were predominantly bar-based, followed by home, street and brothel based. Among the sub-typology, FSWs associated with SHG majority are predominantly street-based, while bar-based FSWs are representing higher in the group than not associated with SHG. It was observed more than 40 percent of them were illiterates in both the groups and majority of them in both the groups are currently married. In Table 1, observation was made that significantly higher percentage of FSWs not associated with SHGs, were reported to have multiple source of income, than the FSWs associated with the SHG.

Across both the groups $>80 \%$ of them had reported their first sexual activity at a younger age, $<20$ years, while $>=80 \%$ of them had got into sex trade after 20 years of their age. The mean number of occasional and regular clients and the mean number of sexual acts are observed to be within a range of 5 - 6 in both the groups.

Table 2 presents the result of different indicators of program exposure and awareness among FSWs associated with SHG and not associated with SHG. The FSWs associated with SHG were significantly having higher knowledge on modes of HIV transmission, higher percentage of them have accessed Drop-in-Centre (DIC), and high percentage of them found to be aware about Joint Health Camp (JHC) and Anti-retroviral Therapy (ART). It was clearly observed that FSWs associated with SHG, turned away from sex when clients had refused to use condom and also stood up 
Table 1. Percent distribution of Female Sex Workers (FSW) by socio-demographic profile in Thane, Maharashtra, India, 2015.

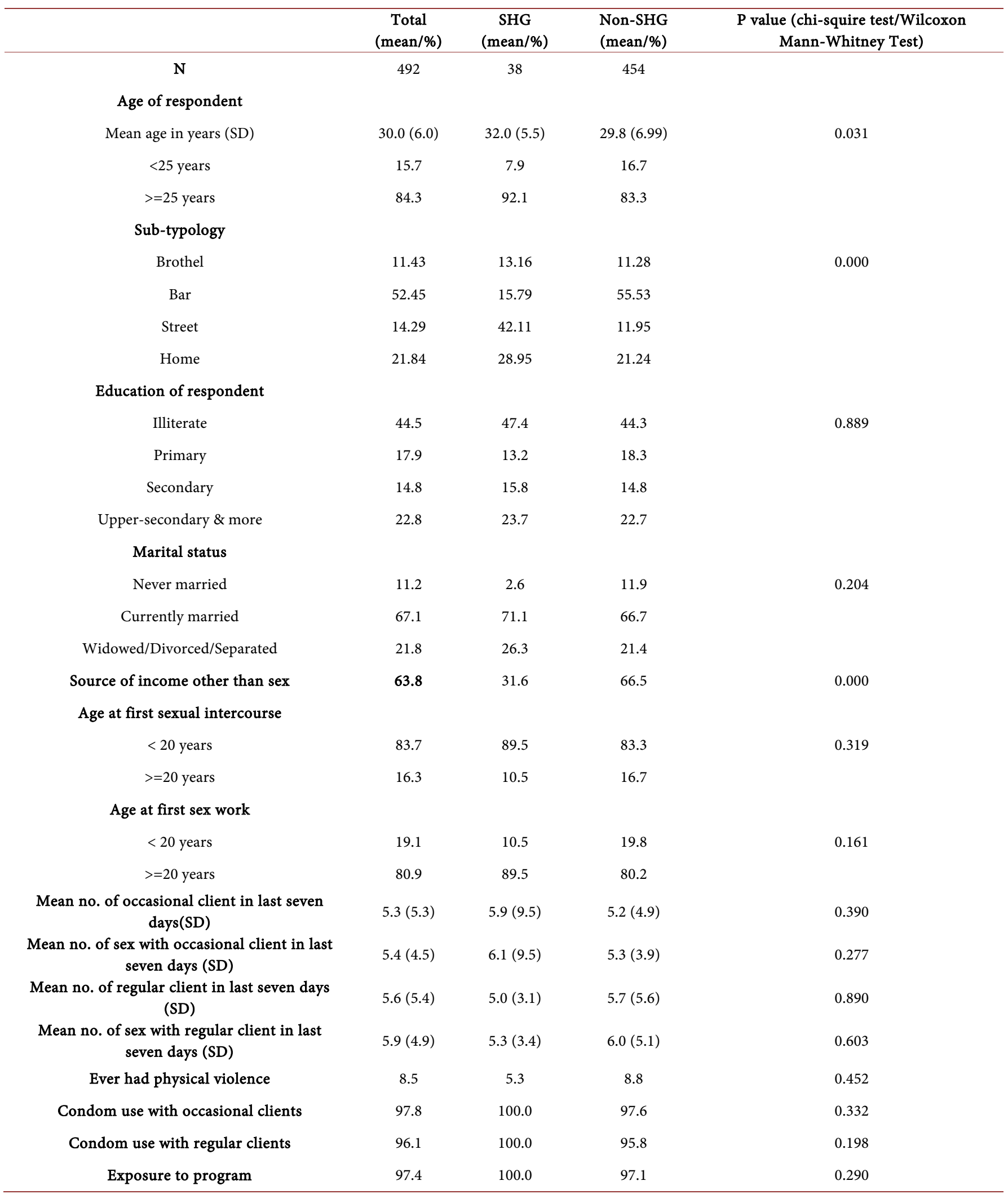

Note: SD standard deviation. 
Table 2. Percent of services utilization among FSW in Thane, Maharashtra, India, 2015.

\begin{tabular}{|c|c|c|c|c|c|}
\hline & Self-help group & $\begin{array}{l}\text { Non-self-help } \\
\text { group }\end{array}$ & $\begin{array}{c}\text { P value (based on } \\
\text { chi-squire test and } \\
\text { Wilcoxon Mann-Whitney } \\
\text { Test) }\end{array}$ & Odds Ratio & $95 \% \mathrm{CI}$ \\
\hline $\begin{array}{c}\text { Knowledge on modes of prevention of } \\
\text { HIV/AIDS }\end{array}$ & 94.7 & 90.9 & 0.562 & $\$$ & \\
\hline Received condom from NGO/TI & 100.0 & 93.4 & 0.154 & $\$$ & \\
\hline Accessed drop in center & 97.4 & 78.2 & 0.003 & $6.534^{*}$ & $(2.148-19.879)$ \\
\hline $\begin{array}{l}\text { Received counseling from a TI on STI, HIV, } \\
\text { condom use and safe sex practices }\end{array}$ & 94.7 & 85.7 & 0.142 & $\$$ & \\
\hline Heard about Joint Health Camp (JHC) & 26.3 & 10.4 & 0.003 & $4.710^{* * *}$ & $(2.122-10.458)$ \\
\hline $\begin{array}{l}\text { Have you accessed any services from JHC in } \\
\text { last } 12 \text { months }\end{array}$ & 95.8 & 89.3 & 0.322 & $\$$ & \\
\hline $\begin{array}{l}\text { Mean number of times visited health camp in } \\
\text { the last } 12 \text { months }(\mathrm{SD})\end{array}$ & $3.3(2.3)$ & $2.8(1.8)$ & 0.490 & $\$$ & \\
\hline $\begin{array}{l}\text { Have you turned away clients when they } \\
\text { refused to use condom during sex }\end{array}$ & 88.9 & 66.8 & 0.006 & $3.762^{*}$ & $(1.269-11.152)$ \\
\hline $\begin{array}{l}\text { Negotiated or stood up against } \\
\text { police/broker/local goonda/client }\end{array}$ & 39.47 & 20.28 & 0.006 & $2.264^{*}$ & $(1.083-4.734)$ \\
\hline Have you heard of ART & 55.3 & 20.0 & 0.000 & $4.548^{* * *}$ & $(2.181-9.482)$ \\
\hline
\end{tabular}

Note: Controlled variables in logistic regression-age of respondent, education, marital status, source of income other than sex; ${ }^{* * *} \mathrm{p}<0.01,{ }^{* *} \mathrm{p}<0.05,{ }^{*} \mathrm{p}<0.1 ;$ OR: Odds Ratio; Only those variables which are significant in bi-variate are considered in multivariate analysis; \$: insignificant in bivariate table so these indicators are not consider for logistic regression and CI: Confidence Interval.

and/or negotiated against police/broker/local goons/atrocities of clients. The odds of the above discussed indicators observed to $>2.3$ times than FSWs not associated with SHGs.

\section{Discussion}

The study was able to show the need for FSWs to be engaged in SHGs, which could facilitate in empowering the community, especially in case of turning away clients when they refuse to use condoms and stood up against police/brokers/local goonda. A key observation of this study is that this study has higher (52\%) representation of bar-based FSWs, rather than the brothel-based, home-based and street-based FSWs [27]. In addition, it was observed predominant of this bar-based FSWs were not associated with the SHG. Due to the limited sample distribution by sub-typology among FSWs associated with SHGs, analysis and interpretation by sub-typology could not be undertaken. Hence, future studies to examine the role of SHGs among FSWs, should take cognizance of the study population and ensure adequate representation of all sub-typologies of FSWs. 
The study has significantly observed that FSWs have the multiple sources of income, including, but not limited to, selling vegetables or flower, daily labourer, domestic help, working in bar, work in massage parlor and beauty parlor is high (66.5\% against $31.6 \%)$ among the FSWs not associated with SHGs. This observation should be interpreted with the sub-typology of FSWs, as it has shown significant association, but which specific typology had greater association; could not be observed due to less representation of FSWs in SHGs in the cohort sample.

With regard to program exposure and subsequent outcome, our study showed consistent findings with the literature available [23] [28]. FSWs associated with SHGs had increasingly heard about health camps, accessed DIC, and heard of Anti-Retroviral Therapy (ART) in significant numbers. While indicators, like knowledge on modes of transmission, received condom, contact by outreach worker and received counseling showing programmatic difference between FSWs associated with SHGs and not associated, but found statistically insignificant. This difference could be due to the long existence of HIV prevention program in Thane, which was able to reach across the spectrum of FSWs, but information on services like ART has not reached due to limited focus of HIV prevention interventions. Hence, it is suggested, TIs working in Thane should strengthen providing information on HIV treatment services, irrespective of their association with SHGs.

\section{Limitation}

This self-reported survey has its in-built limitation such as recall bias. As this is a cross-sectional study by design, causal relationship is not possible. Since the distribution of sub-typologies was not representative among FSWs associated with SHG, analysis by sub-typologies could not be considered. These results however provide an evidence for the role of SHG among specific sub-typologies of FSWs in Thane, India in improving HIV program outcomes.

\section{Conclusion}

The finding has been warranting the TIs role in reaching out to the FSWs not associated with SHGs, more rigorously, to ensure favorable HIV program outcomes. In addition, TIs could also consider facilitating FSWs across typologies to get associated with SHGs, which can enhance the self-esteem of the community and make them less vulnerable to HIV.

\section{Ethical Approval}

Written consent was collected from the participants. The study protocol and the tools were approved by the Manipal University Ethic Committee (MUEC/12/2015 on August 08, 2015).

\section{Acknowledgements}

The United State Agency for International Development (USAID) funded this research 
through the HIV/AIDS Partnership: Impact through Prevention, Private Sector and Evidence-based Programming (PIPPSE) managed by Public Health Foundation of India (PHFI). The author thanks Debasish Chowdhury, Program Manager, PIPPSE, PHFI and Dr. Roopa Shivashankar, Sr. Research Associate, PHFI for their inputs in finalization of the manuscript. Finally we thank the FSWs community for their participation in the study.

\section{References}

[1] Kim, J., Pronyk, P., Barnett, T. and Watts, C. (2008) Exploring the Role of Economic Empowerment in HIV Prevention. AIDS, 22, S57-S71.

https://doi.org/10.1097/01.aids.0000341777.78876.40

[2] Blanchard, J.F., O’neil, J., Ramesh, B.M., Bhattacharjee, P., Orchard, T. and Moses, S. (2005) Understanding the Social and Cultural Contexts of Female Sex Workers in Karnataka, India: Implications for Prevention of HIV Infection. The Journal of Infectious Diseases, 191, S139-S146. https://doi.org/10.1086/425273

[3] Dandona, R., Dandona, L., Kumar, G.A., et al. (2006) Demography and Sex Work Characteristics of Female Sex Workers in India. BMC International Health and Human Rights, 6, 5. http://bmcinthealthhumrights.biomedcentral.com/articles/10.1186/1472-698X-6-5 https://doi.org/10.1186/1472-698X-6-5

[4] Silverman, J.G., Decker, M.R., Gupta, J., Maheshwari, A., Willis, B.M. and Raj, A. (2007) HIV Prevalence and Predictors of Infection in Sex-Trafficked Nepalese Girls and Women. Journal of the American Medical Association, 298, 536-542. https://doi.org/10.1001/jama.298.5.536

[5] Somaiya, P.A., Awate, R.V. and Bhore, P.D. (1990) Socio-Psychological Study of the Prostitutes. Indian Journal of Public Health, 34, 93-97.

[6] Salunke, S.R., Shaukat, M., Hira, S.K. and Jagtap, M.R. (1998) HIV/AIDS in India: A Country Responds to a Challenge. AIDS, 12, S27-S31.

[7] Ramesh, B.M., Moses, S., Washington, R., et al. (2008) Determinants of HIV Prevalence among Female Sex Workers in Four South Indian States: Analysis of Cross-Sectional Surveys in Twenty-Three Districts. AIDS, 22, S35-S44.

https://doi.org/10.1097/01.aids.0000343762.54831.5c

[8] Reza-Paul, S., Beattie, T., Syed, H.U., et al. (2008) Declines in Risk Behaviour and Sexually Transmitted Infection Prevalence Following a Community-Led HIV Preventive Intervention among Female Sex Workers in Mysore, India. AIDS, 22, S91-100. https://doi.org/10.1097/01.aids.0000343767.08197.18

[9] NACO (2014) Annual Report 2013-14. National AIDS Control Organization, Ministry of Health and Family Welfare, Government of India, New Delhi.

[10] Prakash, R., Manthri, S., Tayyaba, S., et al. (2016) Effect of Physical Violence on Sexually Transmitted Infections and Treatment Seeking Behaviour among Female Sex Workers in Thane District, Maharashtra, India. PloS ONE, 1, e0150347. http://journals.plos.org/plosone/article?id=10.1371/journal.pone.0150347 https://doi.org/10.1371/journal.pone.0150347

[11] NACO \& NIMS (2015) India HIV Estimations 2015-Technical Report. National AIDS Control Organization, Ministry of Health and Family Welfare, Government of India, New Delhi.

[12] The Global HIV/AIDS Epidemic (2014) The Henry J. Kaiser Family Foundation, Menlo 
Park.

[13] Kerrigan, D., Wirtz, A., Baral, S., et al. (2012) The Global HIV Epidemics among Sex Workers. World Bank, Washington DC. https://doi.org/10.1596/978-0-8213-9774-9

[14] Erausquin, J.T., Reed, E. and Blankenship, K.M. (2011) Police-Related Experiences and HIV Risk among Female Sex Workers in Andhra Pradesh, India. The Journal of Infectious Disease, 204, S1223-S1228. https://doi.org/10.1093/infdis/jir539

[15] Borman, L.D. (1992) Introduction: Self-Help/Mutual Aid Groups in Strategies for Health. In: Katz, A.H., et al., Self-Help: Concepts and Applications, Charles Press, Philadelphia, xxv.

[16] Katz, A.H. (1979) Self-Help Health Groups: Some Clarifications. Social Science \& Medicine, 13, 491-494. https://doi.org/10.1016/0271-7123(79)90085-3

[17] Kerrigan, D.L., Fonner, V.A., Stromdahl, S. and Kennedy, C.E. (2013) Community Empowerment among Female Sex Workers Is An Effective HIV Prevention Intervention: A Systematic Review of the Peer-Reviewed Evidence from Low-and Middle-Income Countries. AIDS and Behavior, 17, 1926-1940. https://doi.org/10.1007/s10461-013-0458-4

[18] Liamputtong, P., Haritavorn, N. and Kiatying-Angsulee, N. (2009) HIV and AIDS, Stigma and AIDS Support Groups: Perspectives from Women Living with HIV and AIDS in Central Thailand. Social Science \& Medicine, 69, 862-868.

https://doi.org/10.1016/j.socscimed.2009.05.040

[19] Blankenship, K.M., West, B.S., Kershaw, T.S. and Biradavolu, M.R. (2008) Power, Community Mobilization, and Condom Use Practices among Female Sex Workers in Andhra Pradesh, India. AIDS, 22, S109-S116. https://doi.org/10.1097/01.aids.0000343769.92949.dd

[20] Yadav, D., Ramanathan, S., Goswami, P., Ramakrishnan, L., Saggurti, N., Sen, S., et al. (2013) Role of Community Group Exposure in Reducing Sexually Transmitted InfectionRelated Risk among Female Sex Workers in India. PLoS ONE, 8, e78361. http://journals.plos.org/plosone/article?id=10.1371\%2Fjournal.pone.0078361 https://doi.org/10.1371/journal.pone.0078361

[21] Punyam, S., Pullikalu, R.S., Mishra, R.M., Sandri, P., Mutupuru, B.P., Kokku, S.B., et al. (2012) Community Advocacy Groups as a Means to Address the Social Environment of Female Sex Workers: A Case Study in Andhra Pradesh, India. Journal of Epidemiology \& Community Health, 66, ii87-ii94.

http://jech.bmj.com/content/66/Suppl 2/ii87.full.pdf+html

[22] Kalichman, S., Rompa, D. and Cage, M. (2005) Group Intervention to Reduce HIV Transmission Risk Behavior among Persons Living With HIV/AIDS. Behavior Modification, 29, 256-285. https://doi.org/10.1177/0145445504272603

[23] Guha, M., Baschieri, A., Bharat, S., Bhatnagar, T., Sane, S.S., Godbole, S.V., et.al. (2012) Risk Reduction and Perceive Collective Efficacy and Community Support among Female Sex Workers in Tamil Nadu and Maharshtra, India: The Importance of Context. Journal of Epidemiology and Community Health, 66, ii55-ii61. https://doi.org/10.1136/jech-2011-200562

[24] NACO (2014) National Integrated Biological and Behavioural Surveillance (IBBS). National AIDS Control Organization, Ministry of Health and Family Welfare, Government of India.

[25] NACO (2014) District HIV/AIDS Epidemiological Profiles-Maharashtra. National AIDS Control Organization, Ministry of Health and Family Welfare, Government of India.

[26] NACO (2007) Target Intervention under NACP III: Operational Guidelines. National AIDS Control Organization, Ministry of Health and Family Welfare, Government of India.

[27] Saggurti, N., Mishra, R.M., Proddutoor, L., Tucker, S., Kovvali, D., Parimi, P., et al. (2013) 
Community Collectivization and Its Association with Consistent Condom Use and STI Treatment-Seeking Behaviors among Female Sex Workers and High-Risk Men Having Sex with Men/Transgender in Andhra Pradesh, India. AIDS Care, 25, 55-66.

https://doi.org/10.1080/09540121.2012.749334

[28] Nguyen, T.A., Oosterhoff, P., Ngoc, Y.P., Wright, P. and Hardon, A. (2009) Self-Help Groups Can Improve Utilization of Postnatal Care by HIV-Infected Mothers. Journal of the Association of Nurses in AIDS Care, 20, 141-152. https://doi.org/10.1016/j.jana.2008.10.006

Submit or recommend next manuscript to SCIRP and we will provide best service for you:

Accepting pre-submission inquiries through Email, Facebook, LinkedIn, Twitter, etc. A wide selection of journals (inclusive of 9 subjects, more than 200 journals)

Providing 24-hour high-quality service

User-friendly online submission system

Fair and swift peer-review system

Efficient typesetting and proofreading procedure

Display of the result of downloads and visits, as well as the number of cited articles

Maximum dissemination of your research work

Submit your manuscript at: http://papersubmission.scirp.org/

Or contact wja@scirp.org 